\title{
Research on the Design of Agricultural Transportation System Based on Smart City Internet of Things
}

\author{
Na Liao \\ Xi'an International University, Shaanxi Xi 'an, 710077
}

Keywords: Internet of Things; smart city; transportation system

\begin{abstract}
With the development of society and the improvement of people's quality of life, people's emphasis on agriculture has also increased. The development and advancement of science and technology have made the Internet of Things increasingly widely used in smart city agriculture. Through the high-tech and convenience of the Internet of Things, building a smart city agricultural transportation system can not only expand the scope of sales of agricultural products, but also significantly increase the sales volume of agricultural products, improve the rapid development of modern agriculture, and improve the lives of farmers. This paper mainly analyzes the application and methods of the Internet of Things in the design of smart agricultural transportation system, aiming at maximizing the level of agricultural science and technology.
\end{abstract}

\section{Introduction}

With the improvement of people's quality of life, people's quality requirements for vegetables are getting higher and higher. People want to eat fresh and safe vegetables. This not only raises higher requirements for the cultivation of agricultural vegetables, but also sets higher standards for the speed and quality of the transportation of vegetables. Agricultural vegetables are a special product. They will rot and deteriorate and lose their food value. Therefore, they have higher standards for temperature, humidity, gas composition, and packaging. However, in the current agricultural product transportation system, there are still problems such as large investment, unfavorable transportation environment conditions, and long transportation time. Therefore, it is imperative that we strengthen the information management of the transportation system of smart city agriculture. Through the Internet of Things, specific information on agricultural products can be transmitted to information sensing devices through laser scanning. According to specific procedures set, agricultural products can be intelligently identified, located and supervised, and can be based on the quality and changes of agricultural products. Real-time adjustments to the transport environment can maximize the quality and shelf life of agricultural products. The full application of the Internet of Things in a smart agricultural transportation system not only greatly enhances the transportation efficiency of agricultural products, but also reduces the loss of agricultural products during transportation and minimizes transportation costs [1].

\section{Factors Influencing the Quality of Agricultural Products in Transportation System}

Vibration. Agricultural products are products that are easily damaged in transit. During transportation, because of unfair road conditions, low driver skills, imperfect packaging, and other objective factors, violent jolting of transport vehicles can easily cause mechanical damage to the surface of agricultural products, rendering microorganisms organically accessible and entering agricultural products. Even a tiny wound will accelerate the speed of decay of agricultural products, reduce the shelf life of agricultural products, and increase the damage rate of agricultural products and the cost of transportation.

Temperature. In addition to vibration, the temperature requirements and sensitivity of agricultural products during transportation are also very high. Excessive temperatures can easily damage agricultural products. At present, in the transportation of agricultural products, the general preservation method is to reduce the temperature of the transportation environment, keep the 
agricultural products fresh at an appropriate temperature, and extend the shelf life. According to the International Institute of Refrigeration, vegetables that require low temperatures and transport for more than 6 days are stored at the same room temperature as low temperature storage. [2] as shown below:

Table 1: Recommended transport temperature of some fresh vegetables in cold transport

\begin{tabular}{|c|l|l|l|l|l|l|l|l|}
\hline $\begin{array}{l}\text { Vegetable } \\
\text { species } \\
\text { Recommended } \\
\text { temperature }\end{array}$ & cauliflower & Cabbage & lettuce & spinach & chili & $\begin{array}{l}\text { cucum } \\
\text { ber }\end{array}$ & $\begin{array}{l}\text { kidney } \\
\text { bean }\end{array}$ & Shi Yubai \\
\hline 1-2d & $0-8$ & $0-10$ & $0-6$ & $0-5$ & $7-10$ & $10-13$ & $5-8$ & $0-5$ \\
\hline $2-3 d$ & $0-4$ & $0-6$ & $0-2$ & $\begin{array}{l}\text { Not } \\
\text { recomm } \\
\text { ended }\end{array}$ & $7-8$ & $10-13$ & $\begin{array}{l}\text { Not } \\
\text { recomme } \\
\text { nded }\end{array}$ & $0-2$ \\
\hline
\end{tabular}

Humidity. Humidity is the amount of water contained in agricultural products. The long period of time during which agricultural products are collected, packaged, loaded and transported will inevitably result in the loss of some agricultural products. At present, the main method of maintaining moisture content in the transportation of agricultural products at home and abroad is to pad polyethylene film in the packed water carton. In addition, the agricultural products are regularly watered manually during transportation to ensure the moisture content and preservation of agricultural products. time.

Handling. Agricultural products are generally fragile and vulnerable to damage, especially in the process of loading and unloading. Due to the incorrect handling methods, excessive transportation efforts, and the objective reasons that the transportation personnel do not care about, the agricultural products are damaged, resulting in loss of value and in disguise. Increased transportation costs and brought great economic losses to users.

\section{Design Principles of Internet of Things in Agricultural Transportation System}

Actually, the principle of application of the Internet of Things is to specify the specific information of agricultural products, and then through the sensor equipment such as laser scanners to convey the information of agricultural products to the Internet. Finally, the user receives the conveyed agricultural products through a specific application program. After the information, after data analysis, understand and master the basic information of agricultural products, make adjustments and adjust the corresponding program. The application of the Internet of Things realizes the intelligent management of agricultural products transportation through mutual exchange and sharing of information. On this basis, it not only greatly enhances the speed and efficiency of the transportation system, it also enables the machinery and equipment to more accurately scan and collect information on agricultural products, and can quickly respond to this, and timely feed the collected agricultural product information back to the network system. In the process, the efficiency of the agricultural product transportation system has been greatly improved. [3]

The full application of the Internet of Things not only realizes the intelligent management of the transportation system, but also fully satisfies the high standards for the environmental conditions of agricultural products in the transportation process. Through the scientific and intelligent management methods, the Internet of Things responds to the driver's traffic conditions and vehicle conditions in a timely manner so that the driver can understand the situation of the road surface without affecting the driver's attention and greatly avoid the occurrence of traffic accidents. The safety of agricultural product transportation systems. The Internet of Things connects items information and communication networks and applications to each other, strengthens the exchange and connection of information between each other, and strengthens the induction and reflection of the scientification of agricultural products. 


\section{The Internet of Things in the Design of Agricultural Transportation System}

Through the design and application of the Internet of Things in the agricultural product transport system, the entire process of the agricultural product transport system has been realized in an institutionalized and scientific manner, which avoids frequent mistakes and inefficiencies in the manual management, and improves the efficiency of transport and transportation. With quality, the management efficiency of the agricultural product transportation system gradually shows an increasing trend. Through the technology-based equipment of the advanced technology course of the Internet of Things, relevant data information monitored during the transportation process is timely fed back to relevant applications for reference by users.

In realizing the design process of the Internet of Things for agricultural product transportation systems, it is necessary to monitor all process information such as planting, maturing, picking, selling, and transportation of agricultural products, and collect detailed and accurate relevant information as reference data to keep abreast of agricultural products. State, to provide fresh and high-quality vegetables for long-distance consumers.

After the ripening of agricultural products, after each agricultural product is carefully inspected to ensure completeness, a corresponding bar code is designated and pasted on the agricultural product so that each agricultural product has a unique identification bar code. Through this bar code, the product can be Specific information is communicated to the sensor; after entering the transport phase, relevant information is collected through the vehicle's FRID and driver's FRID. The information parameters of the agricultural products and the information parameters of the vehicles and the drivers are transmitted to the application programs through sensors, and the results of the analysis of the agricultural products are judged by using the analysis results of these data information as references. Users can obtain this information through remote communication devices and achieve remote control.

With the development of science and technology, barcodes are increasingly used in agriculture. Agricultural products are identified by affixing specific bar codes to agricultural products. The application of the Internet of Things in the transportation system reads bar codes through the machine, which takes only 2 seconds, which shortens the time by 8 seconds compared to the manual reading of the bar code, greatly improving the efficiency and effectiveness of the work.

The user can grasp the situation of the transport vehicle at any time through the application of the agricultural product transport system, and conduct dialogue and remote communication with the driver through the communication system, and fully understand the environmental changes of the agricultural products during transportation, such as temperature, air humidity, etc. After a scientific analysis of these data, timely adjustment plans were made.

\section{Practical Steps of the Internet of Things in Agricultural Transportation System}

The perception network is mainly composed of three cameras, a camera, a communicator, and a FRID reader, and is finally implemented in practice. These three kinds of equipment are all vehicle-mounted applications. The three are indispensable, cooperate with each other, share information with each other, and jointly implement the implementation of the agricultural product transportation system. The camera is mainly installed in the cabin of the agricultural product and is responsible for monitoring the changes in the conditions inside the vehicle and the quality changes of the agricultural products. It also monitors the basic conditions and road conditions of the transport vehicle at all times. The communication device is mainly used for communication between the driver of the vehicle and the managers of the network management center. , exchange information with each other, communicate in a timely manner, and timely feedback on their own situation changes; FRID readers mainly detect changes in the environment such as humidity, temperature, etc., and then upload the detected data information if the vehicle's environmental data occurs. If there is a big change, an alert will be issued and the situation will be fed back to the manager in a timely manner. 
The mobile communication network consists of a wireless access point AP, an antenna, and a mobile communication core network. The main role of mobile communications networks plays a role in transmission. [4] Mainly convey the information of the agricultural products collected by the perception network to the managers of the network management center in the specific conditions of the transportation process and the changes in the transportation environment; then the management personnel of the network management center pass the adjusted reference data through the mobile communication network. In communicating to transport vehicles, make adjustments to the vehicle transportation environment. The mobile communication network has a strong connection role. The agricultural product transportation system uses the mobile communication network to realize the exchange of information and managers and exchange of information, ensuring the complete realization of the agricultural product transportation system.

The network management center is a data center. All the information collection and data analysis of agricultural products are realized through the network management center. In addition, after analyzing the data, the network management center makes adjustment plans and communicates the plan to the network management center. transport vehicle. The network management center consists of a large database that can analyze and compare the collected information and database to analyze and calculate the reference data. The system server of the network management center provides the necessary information for the entire process of the transportation system and the completion of each link. Technical support platform. The query terminal and management terminal of the network management center cooperate with each other. The inquiring terminal has a powerful query function, and is connected to each agricultural product transport vehicle to provide the management terminal with the corresponding data information of the agricultural product transport situation; after the management terminal analyzes the data information inquired about by the inquiring terminal, it performs classification management and is convenient for the Reference data storage and application.

The agricultural product transportation system uses the RFID technology, and it takes only 0.1 second to identify agricultural products. On the road of agricultural products transportation, there are FRID readers everywhere on the passing highways, so you can know the specific location information of transport vehicles at any time and monitor and protect the transport vehicles. If there are any errors in the transport vehicles, such as product loss, when taking the wrong route, the network management center can contact the driver of the vehicle in time through the mobile communication network. The driver can correct the error in time and avoid causing greater losses.

The full application of IoT technology in the smart agricultural transportation system not only realizes the information and intelligence of smart agriculture, but also improves the efficiency of agricultural production, and it also improves the protection of agricultural products in the transport process and reduces the transportation process. The damage has greatly increased the benefits of agricultural production. The application of the Internet of Things has greatly improved the information query system for agricultural products in the transportation process, strengthened the communication and communication between transport vehicles and management center personnel, avoided the occurrence of work errors, and improved work efficiency.

\section{Conclusion}

The design and application of the Internet of Things in the transportation system of smart agriculture helped the modern agricultural transportation system quickly realize intelligence and information management. Through the Internet of Things system, the use of cameras, FRID sensors and other equipment, scientific monitoring of changes in the demand for humidity, temperature, air conditions, etc. during the transportation of agricultural products, and the results of the monitoring are communicated to the specialized network system program in real time. After analyzing these data, the transport environment is adjusted and adjusted accordingly to optimize the transportation environment of agricultural products. The application of the Internet of Things in agricultural product transportation systems is of great significance for improving the efficiency of agricultural product transportation and reducing the losses caused during transportation. 


\section{Acknowledgements}

The 2017 Xi'an Social Science Planning Project "Study on Xi' an Smart City and Collaborative Innovation Construction Path in the Era of Internet of Things".

Project number: 17IN08.

\section{References}

[1] Deng Wentao, Zhao Yucheng, Yuan Shuai, Ma Binqiang, Zhu Wei, Li Yu, Yuan Chao, Zhao Zhonglin. Development and Application of Wisdom Agriculture Based On Internet of Things [J]. Agricultural Network Information, 2014, (12): 9- 12.

[2] Jiang Ning. Design of Intelligent Transportation Training System Based On Internet of Things [J]. Internet of Things Technology, 2017, 7(09): 117-118.

[3] Shi Lianmin, Chen Zhifeng, Gai Zhihua. Application of Internet of Things in Wisdom Agriculture[J]. Journal of Agricultural Mechanization Research, 2013, 35(06): 250-252.

[4] Peng Cheng. Research On the Development Strategy of Smart Agriculture Based On Internet of Things Technology[J]. Journal of Xi'an University of Posts and Telecommunications, 2012, 17(02): 94-98.

[5] Li Daoliang. Internet of Things and Smart Agriculture[J]. Agricultural Engineering, 2012, 2(01): $1-7$. 